\title{
Generation of solar radiation values for use in weather files of crop simulation models ${ }^{1,2}$
}

\author{
A. M. Esnard, ${ }^{3}$ L. R. Pérez-Alegría, ${ }^{4}$ \\ Fred H. Beinroth ${ }^{5}$ and Ricardo Goenaga ${ }^{6}$
}

\begin{abstract}
A user friendly computer program for generating solar radiation values was developed for three sites (Mayagüez, Ponce and Isabela) in Puerto Rico. The program produces solar radiation data compatible with that of the weather files of the crop models in the Decision Support System for Agrotechnology Transfer (DSSAT), developed by the International Benchmark Sites Network for Agrotechnology Transfer (IBSNAT). The program randomly generates solar radiation values within a range determined by statistical analysis of available observed solar radiation data. A chi-square goodness-of-fit test showed that, for a given Julian day and site, the random values produced are uniformly distributed (non-biased) over the pre-determined confidence interval range $(\alpha=0.05)$. Results also indicate that the annual trend in the program-generated solar radiation values throughout the year was similar to that of the observed values. Using the randomly generated solar radiation values, the output parameters (pod yield, seed yield, shelling percentage, weight per seed, seed number, maximum LAI, biomass, stalk and harvest index) of the DSSAT dry bean model were similar to the variables generated with observed solar radiation data.
\end{abstract}

\section{RESUMEN}

Generación de radiación solar para modelos de simulación de cultivos

Se desarrolló un programa de computadora de uso fácil para generar valores de radiación solar en tres sitios de Puerto Rico (Mayagüez, Ponce e Isabela). El programa genera un archivo de clima compatible con los que usan los modelos de simulación de crecimiento de cultivos en el "Decision Support System for Agrotechnology Transfer (DSSAT)" desarrollado por el proyecto "International Benchmark Sites Network for Agrotechnology Transfer (IBSNAT)". El programa genera datos de radiación solar en forma aleatoria usando los parámetros obtenídos mediante análisis estadísti-

${ }^{1}$ Manuscript submitted to Editorial Board 5 May 1993.

${ }^{2}$ This research was funded by the USDA/CSRS Special Research Grants in Tropical and Subtropical Agriculture (PL-89-106) managed by the Caribbean Basin Administrative Group (CBAG).

${ }^{3}$ Former Graduate Student, Department of Agronomy and Soils, University of Puerto Rico, Mayagüiez, P.R. 00680.

${ }^{4}$ Agricultural and Environmental Engineer, Department of Agricultural Engineering, University of Puerto Rico, Mayagüez, P.R, 00680.

${ }^{5}$ Professor of Soil Science, Department of Agronomy and Soils.

${ }^{6}$ Research Plant Physiologist, USDA/ARS, Mayagüez, P.R. 00681. 
cos de valores medidos en el campo. Una prueba de Ji-cuadrado indicó que, para una día juliano cualquiera, los valores generados por el programa están distribuidos uniformemente (no hay sesgo) para un espectro de valores predeterminados y un nivel de significancia del 0.05 . Los resultados también indican que el patrón de distribución de valores de radiación solar es similar al de los valores observados. Los resultados del modelo de simulación en habichuela de DSSAT son similares a los resultados obtenidos con los valores de radiación solar observados en los tres sitios.

\section{INTRODUCTION}

In modern agriculture, efforts are being made to improve production and productivity without time-consuming and costly research based on conventional trial and error methods. Computer applications such as crop simulation models and decision support systems can lead to timely decision making on agricultural production issues, and significantly accelerate the decision process. Crop simulation models simulate crop development processes (such as photosynthesis and plant growth) as accurately as possible by expressing these processes mathematically. A crop simulation model can therefore simulate daily crop growth, development and final yield in any fully specified environment, taking into account soil, weather and management inputs, cultivar types and season $(1,10,11,17)$. The models can thus be used to answer "what if" questions, without the loss of considerable time, money and other resources in obtaining answers from field experiments $(1,9,19)$.

Several crop simulation models (maize, rice, soybean and drybean) have been combined with soil and weather databases and other computer applications to form a Decision Support System for Agrotechnology Transfer (DSSAT). DSSAT allows the user to access any of the crop simulation models through the use of a common data base which contains standardized input data $(6,7,8,10)$. Despite the importance of these crop models and their applications, the scarcity of accurate weather data, particularly that of solar radiation (8), is the main limitation to their use. Beinroth (1990) suggested that one possible solution to this lack of data is its artificial generation with innovative techniques. The importance of such an approach cannot be overstated. For the past three decades, the development and use of weather generators and models to accurately predict solar radiation for different sites has proved to be very effective $(2,4,15,16)$.

In the Caribbean, research on the quantification of solar radiation has been limited. The most recent work was done by Shih and Cheng (1989) and this involved the use of a regression technique, an average of historical data and a time series analysis to synthesize a series of climatic data for some sites in Puerto Rico. The specific application was for input into a modified Blaney-Criddle equation, which in turn estimated evapotranspiration. In the case of missing data, that from 
adjacent sites was used. This latter method is not always applicable since it does not take the spatial variation within is region (as is common in the Caribbean islands) into account. Hence a proper methodology, which is not data (i.e. solar radiation) dependent had to be developed that would accurately predict solar radiation values for different sites in Puerto Rico.

The objective of this study was to develop a computer program to generate solar radiation values compatible with the weather files format of available DSSAT crop simulation models.

\section{PROCEDURE}

A computer progxam embodying mathematical equations developed by Choudhury (2) was written in Fortran (5) to estimate the average total solar radiation for each Julian day of the year for three sites in Puerto Rico. The significance of the difference between the observed values and the program-generated mean values was determined by using a pairwise t-test comparison $(12,18)$.

By using the observed data for the three sites (up to 7 years of data), the standard deviation and $95 \%$ confidence intervals were calculated for each Julian day. The computer program was then modified to randomly generate a different value (within the calculated range) on every run by inclusion of a random generator function (6). In this random generator, the series of solar radiation values generated depended on the starting or "seed" value, X. This seed value could be any decimal value between 0 and 1 . To ensure that solar radiation data were being generated randomly and uniformly over the pre-calculated confidence interval range, the program was run 50 times with starting or "seed" values ranging from 0.02 to 0.98 . The chi-square test was performed on the generated solar radiation values for different Julian days. The hypotheses were:

Ho: solar values are uniformly distributed over the observed range

$\mathrm{Ha}$ : solar values are not uniformly distributed over the observed range

The computer program was further modified to allow either replacement of the variable "SOLRAD" (table 1) or addition of new solar radiation values (in the case of missing values) to a DSSAT weather file specified by the user. The dry bean simulation model (installed in DSSAT) was then run with weather files for Isabela containing (i) observed solar radiation data for the year 1990 and (ii) solar radiation values randomly generated by the solar radiation model. In the latter case, six weather files were created and used, each with a different set of randomly generated solar radiation values. 
TABLE 1. - Weather data variables and their Fortran formats in DSSAT weather files (Adapted from IBSNAT, 1990a)

\begin{tabular}{lll}
\hline $\begin{array}{l}\text { Variable } \\
\text { name }\end{array}$ & \multicolumn{1}{c}{$\begin{array}{l}\text { FoRTRAN } \\
\text { Format }\end{array}$} & \multicolumn{1}{c}{ Description } \\
\hline Format for line 1 of weather data file: & \\
INSTW & A2 & Code for institute ID \\
STATW & A2 & Code for weather station ID \\
XLAT & IX,F6.2 & Latitude of station \\
XLONG & IX,F6.2 & Longitude of station \\
PARFAC & IX,F5.2 & Factor to convert $\mathrm{MJ} / \mathrm{m}^{2}$ to $\mathrm{E} / \mathrm{m}^{2}$ \\
PARDAT & IX,F5.2 & Indicator of PAR data $(0.00=\mathrm{No})$ \\
Format for all other lines of weather data: & \\
INSTW & A2 & Code for institute ID \\
STATW & A2 & Code for weather station $\mathrm{LD}$ \\
IYR & IX,I2 & Year for which weather data is being read \\
UL & IX,I3 & Julian date of weather record in data file \\
SOLRAD & IX,F5.2 & Daily total solar radiation, $\mathrm{MJ} / \mathrm{m}^{2}$ \\
XTMAX & IX,F5.1 & Daily value of maximum air temperature, ${ }^{\circ} \mathrm{C}$ \\
XTMIN & IX,F5.1 & Daily value of minimum air temperature, ${ }^{\circ} \mathrm{C}$ \\
XRAIN & IX,F5.1 & Daily total precipitation, mm $/$ day \\
XPAR & IX,F6.2 & Daily total PAR, if available, $\mathrm{E} / \mathrm{m}^{2}$ \\
\hline
\end{tabular}

The confidence intervals of the crop model output parameters (pod yield, seed yield, shelling percentage, weight per seed, seed number, maximum leaf area index (LAI), biomass, stalk and harvest index) generated with the use of the solar radiation model-generated values were calculated and compared to the crop model output parameters generated with use of observed (measured) solar radiation data. A menudriven interface was developed using dBASE IV to facilitate the process of running the solar radiation model and viewing and printing output data.

\section{DATA SOURCE}

Climatic data for input into Choudhury's equations were obtained from three main sources. The National Climatic Data Center (NCDC) in Ashville, North Carolina, provided satellite measurements of atmospheric variables such as ozone path length, precipitable water, turbidity and cloud cover. Data provided by the former Center for Energy and Environment Research (CEER) of the University of Puerto Rico consisted of total and diffuse hourly radiation, from measurements collected from 1976 to 1981 for Mayagüez and between 1978 to 1981 for Ponce. Data provided by the Agricultural Research Service of the United States Department of Agriculture consisted of total daily solar radiation for Isabela collected from July 1989 to February 1992. 
MODEL MATHEMATICS

Modeling total daily radiation

Choudhury (2) developed a model to simulate total insolation as it is affected by atmospheric parameters, surface albedo and cloud cover. The equations and substitutions used in Choudhury's model follow:

$$
H=H_{O} \frac{\left[1-\sum_{1}^{5} \varepsilon_{j}\right]\left[\left(1-s_{d}\right)\left(1-s_{d}\right)+0.5 s_{c}+0.75 s_{d}\right]}{1-\alpha_{s} \frac{(0.0658+\beta)}{(0.9606+\beta)}}\left[\frac{1-c+c r_{c l}(\alpha)}{1-c \alpha_{s} \alpha_{c l}}\right]
$$

where

$\mathrm{H}=$ total solar radiation $\left(\mathrm{KJm}^{-2}\right.$ day $\left.^{-1}\right)$,

$\mathrm{H}_{0} \quad=$ extraterrestrial insolation $\left(\mathrm{KJm}^{-2} \mathrm{day}^{-1}\right)$,

$\varepsilon_{j} \quad=$ coefficients of atmospheric absorption for water vapor $(j=1)$, carbon dioxide $(j=2)$, ozone $(j=3)$, oxygen $(j=4)$ and aerosols $(j=5)$,

$\mathrm{s}_{\mathrm{a}} \quad=$ Rayleigh's coefficient of dispersion

$s_{d} \quad=$ coefficient of dispersion for aerosols

$\alpha_{\mathrm{cl}} \quad=$ cloud albedo for surface reflected diffuse radiation

$\alpha_{\mathrm{S}} \quad$ =superficial albedo

$\beta \quad=$ Angstrom turbidity

c $\quad$ fractional cloud factor

$T_{\mathrm{cl}}(\alpha)=$ cloud transmission coefficient at a particular latitude.

Choudhury used the relationship developed by Hoyt (4) for generating the absorption factors $\left(\varepsilon_{j}, j=1, ., 5\right)$ and the coefficients $s_{a}$ and $s_{d}$ :

$$
\begin{aligned}
& \varepsilon_{1}=0.11(0.088 m w+0.00631)^{0.3}-0.0121 \\
& \varepsilon_{2}=0.00235(126 m+0.0129)^{0.26}-0.00075 \\
& \varepsilon_{3}=0.045(u m+0.000834)^{0.38}-0.0031 \\
& \varepsilon_{4}=0.0075\left(m^{*}\right)^{0.875} \\
& \varepsilon_{5}=0.05\left(1-g^{*}\right) \\
& s_{d}=1-g^{m *} \\
& s_{a}=\frac{0.606 m^{*}}{6.43+m^{*}}
\end{aligned}
$$

where

$$
\begin{aligned}
& m=\text { relative air mass } \\
& w=\text { atmospheric precipitable water }(\mathrm{cm}) \\
& u=\text { thickness of ozone layer in the region }(\mathrm{cm}) \\
& m^{*}=\text { pressure corrected air mass (mbar) } \\
& g \quad=\quad \text { function of turbidity. }
\end{aligned}
$$


$g$ is given by

$g=0.9843-1.149 \beta$

The relative air mass is given by

$m=\sqrt{(797 \sin \alpha)^{2}}+1595-797 \sin \alpha$

The pressure corrected air mass ( $m^{*}$ ) is given by

$m^{*}=\frac{m P}{1013}$

where $\mathrm{P}$ is the atmospheric pressure (mbar). The cloud transmission coefficient, $T_{\mathrm{cl}}(\alpha)$ is given by

$T_{\mathrm{cl}}(\alpha)=\frac{0.97(2+3 \sin \alpha)}{4+0.6 \tau}$

where $\sin \alpha$, a function of the latitude $(\phi)$ and the solar declination angle $(\delta)$ is given by the expression

$$
\sin \alpha=\frac{1}{0.105+\frac{1.275}{\cos (\phi-\delta)}}
$$

The solar declination angle is given by

$\delta=0.38647-0.792624 \cos t+0.377853 \cos 2 t+0.0301224 \cos 3 t$

$+23.259526 \sin t+0.131544 \sin 2 t+0.167013 \sin 3 t$

where $t$ is a function of the day of the year and is represented by the following expression:

$$
t=\frac{2 \pi(N-80)}{365}
$$

$\mathrm{N}$ is the Julian day (where its value ranges from $N=1$ for January 1st to $N=365$ for December 31 st).

The cloud albedo for surface reflected diffuse insolation $\left(\alpha_{\mathrm{cl}}\right)$ is given by

$$
\alpha_{\mathrm{cl}}=\frac{0.6 \tau}{4-0.6 \tau}
$$

where $t$ is the optical thickness and is dependent on cloud type. The extraterrestrial daily insolation $\left(\mathrm{H}_{0}\right)$ is given by

$$
H_{0}=\frac{116985 r^{\circ}}{\pi}[h \sin \phi \sin \delta+\cos \phi \cos \delta \sinh ]
$$

where $r$ is the mean distance from the sun to the earth and $w_{s}$ is the sunset hour angle:

$$
\begin{aligned}
& r=1-0.0335 \sin \left[\frac{2 \pi(N-94)}{365}\right] \\
& h=\pi-\cos ^{-1}(\tan \phi \tan \delta)
\end{aligned}
$$


Choudhury's model as described by the equations above utilizes parameters that independently affect the solar radiation arriving at the earth's surface. For the purpose of the present work, Choudhury's model was considered the most suitable. The main reasons for this were (i) the fact that the model does not contain empirical constants which are specific to a particular location or climate and (ii), that the required input atmospheric values are known or can be estimated with appreciable accuracy for many regions in the Caribbean from satellite measurements $(3,15)$.

\section{RESULTS AND DISCUSSION}

With site specific atmospheric data for input into Choudhury's model, mean solar radiation values can be generated for different sites in Puerto Rico. Results from the two-tailed t-test for Isabela ( $t=15.019$, $\mathrm{p}<0.001, \mathrm{r}=.979$ ), Mayaguez $(\mathrm{t}=15.869, \mathrm{p}=0.001, \mathrm{r}=0.981$ ) and Ponce $(\mathrm{t}=16.189, \mathrm{p}=0.001, \mathrm{r}=0.981)$ indicate that there is a high correlation between the model-generated mean values and observed (measured) mean values. This conclusion is based on the coefficient of correlation values $r$, which indicates the degree of association between the two sets of mean values, and not on the $t$ value. The modified $t$ value is given by the following equation (18):

$$
I=\frac{r}{\sqrt{\frac{\left(1-r^{2}\right)}{n-2}}}
$$

In addition, the trend in the solar radiation values generated by the model compares closely with that of the observed values for the sites being evaluated (fig. 1, 2,3). Different trends for different sites is most likely due to different cloud patterns at the different sites.

While the use of these mean values (generated by the use of Choudhury's equations) in the weather files of crop simulation models may be suitable for individual 1-year simulations, they are not suitable when 10 or more years of weather data are needed for long-term strategy analyses. Besides, this would be erroneous since the statistical analyses of the observed data for the different sites showed that there is much day-to-day and year-to-year variation in the solar radiation values.

Results from the chi-square test (table 2) performed on the values generated by the computer program showed that all calculated chisquare values were less than 16.92 (i.e. $\mathrm{X}^{2}{ }_{9}, 0.05$ ). Hence the null hypothesis was not rejected at the $\alpha=0.05$ level and it can be concluded that for a given Julian day, the randomly generated solar radiation values were uniformly distributed over the predetermined range. 


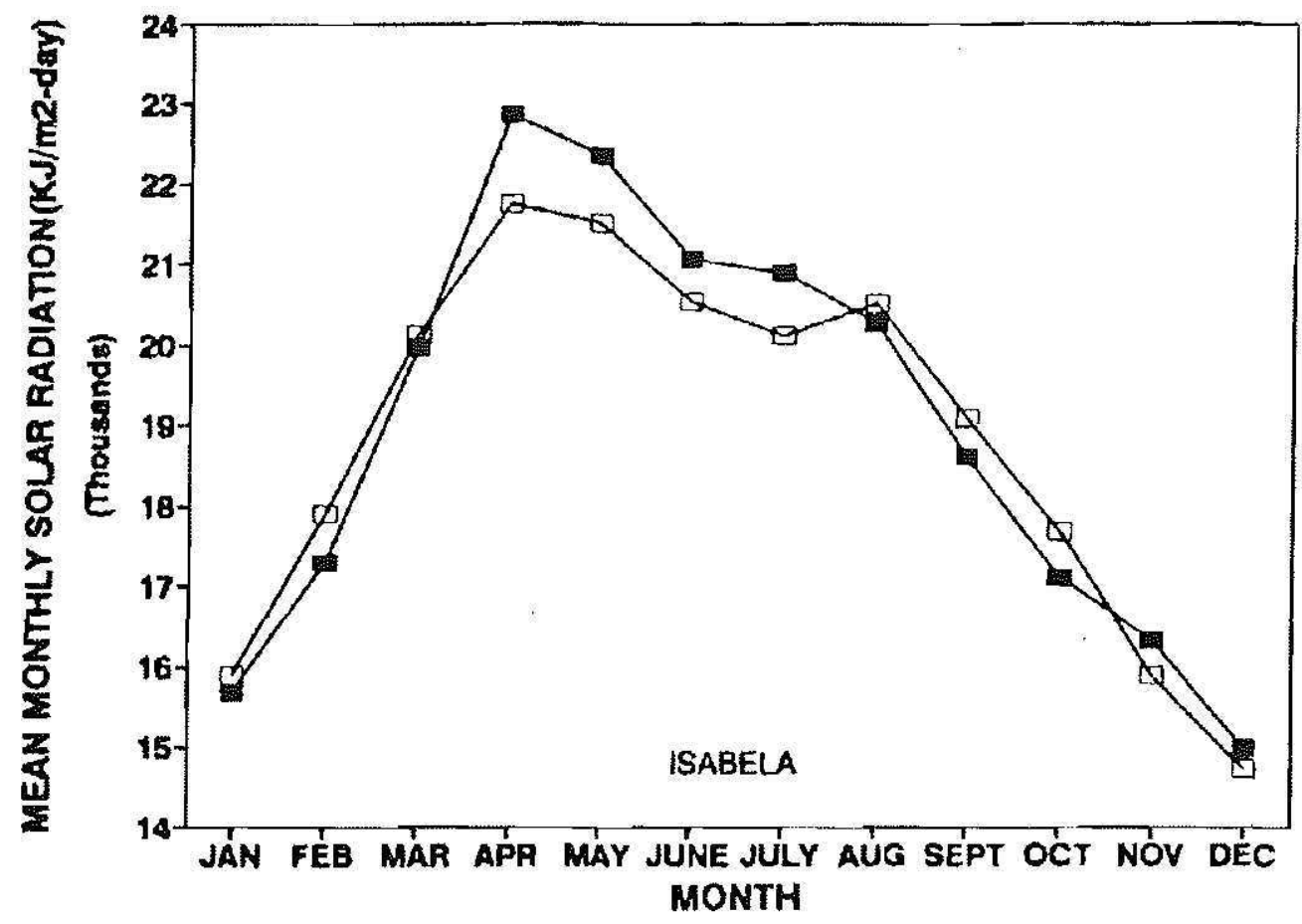

- OBSERVED MEANS $\square$ MODEL MEANS

Fig. 1. - Annual trend in model-generated and observed mean monthly solar radiation for Isabela.

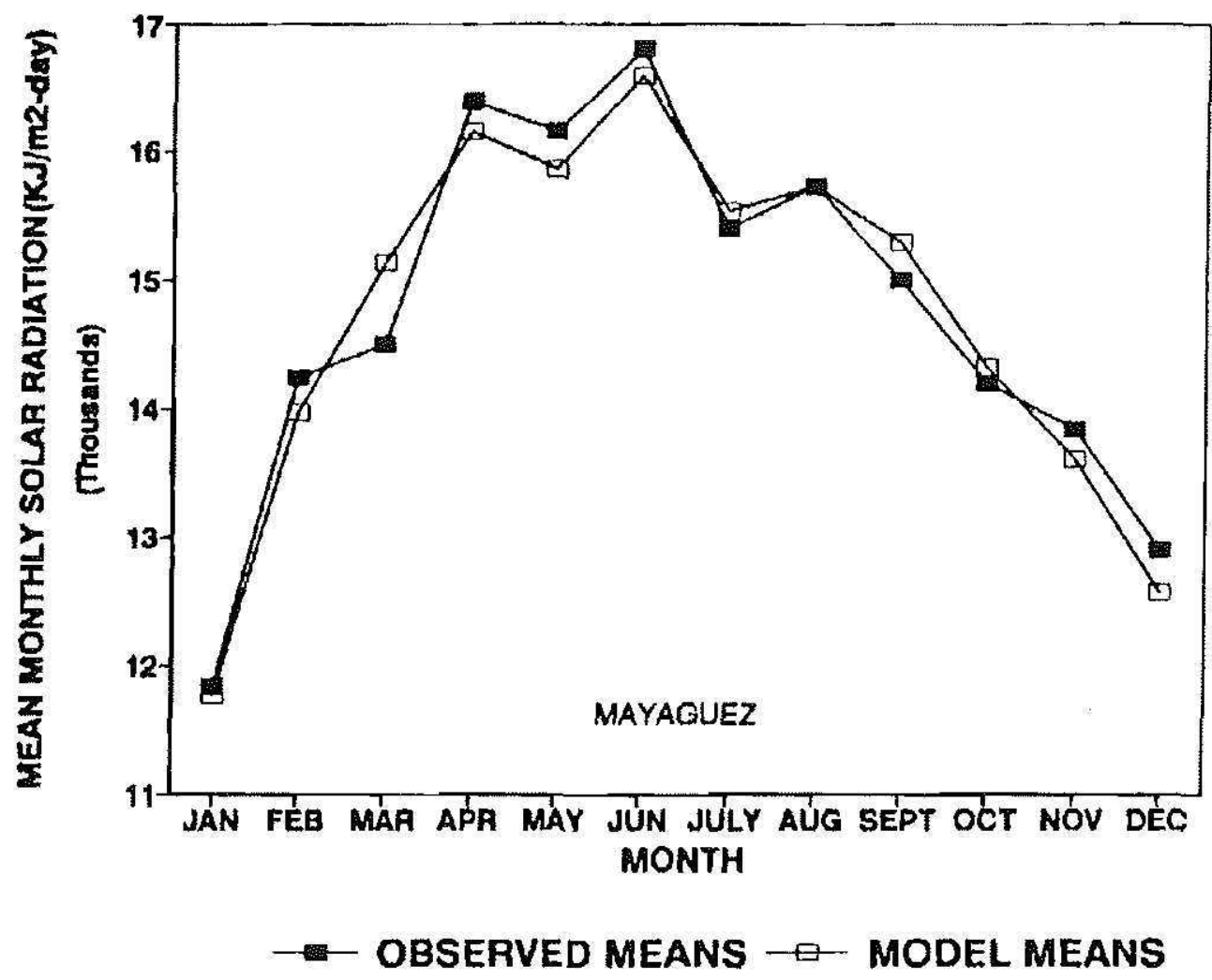

Fig. 2.-Annual trend in model-generated and observed mean monthly solar radiation for Mayaguez. 


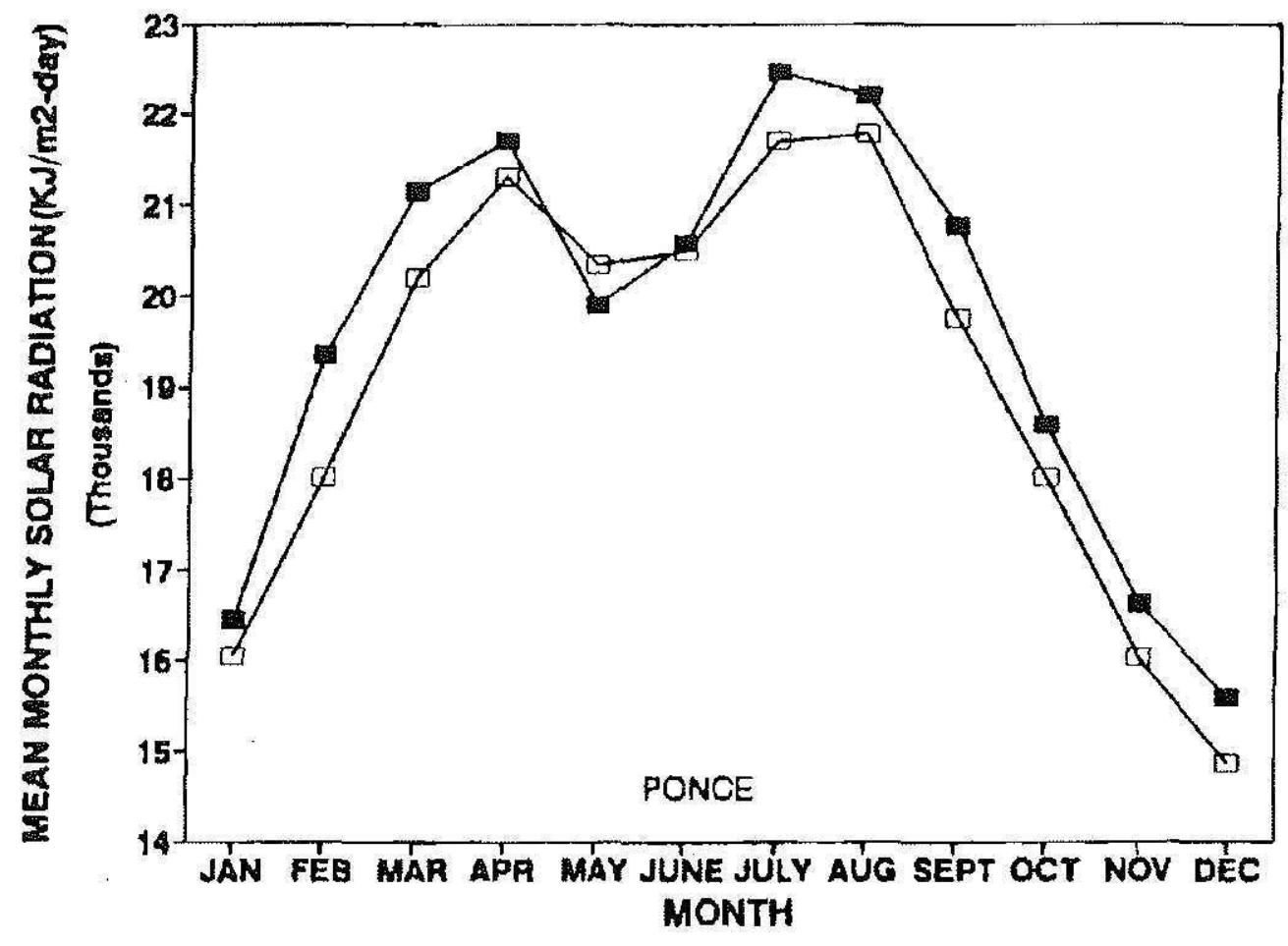

\section{- OBSERVED MEANS - MODEL MEANS}

Fig. 3.-Annual trend in model-generated and observed mean monthly solar radiation for Ponce.

The computer program successfully replaced existing solar radiation values or, in the case of missing values, added new values to a specified DSSAT weather file. Table 3 summarizes the output parameter values (such as seeds per pod) and the mean and confidence intervals of these values generated by use of randomly generated solar values and observed solar radiation data. The crop model output generated by using random solar model values are similar to that generated when observed solar radiation values are used. It is noteworthy that the values of the parameters viz. flowering date, first pod, full pod and seeds per pod remained unchanged.

TABLE 2.-Chi-square test results of the random model output for four randomly selected Julian days

\begin{tabular}{cccccc}
\hline \multicolumn{7}{c}{ Calculated chi-square $\left(\mathrm{X}^{2}\right)$ value for Julian day } & \\
Site & 61 & 122 & 244 & 366 & $\begin{array}{c}\text { Tabular } X^{2} \\
\text { d.f. }=9, \\
\alpha=0.05\end{array}$ \\
\hline Isabela & $2.40 \mathrm{~ns}$ & $4.80 \mathrm{~ns}$ & $0.20 \mathrm{~ns}$ & $5.60 \mathrm{~ns}$ & 16.92 \\
Ponce & $2.40 \mathrm{~ns}$ & $5.20 \mathrm{~ns}$ & $1.81 \mathrm{~ns}$ & $5.60 \mathrm{~ns}$ & 16.92 \\
Mayaguez & $5.43 \mathrm{~ns}$ & $4.46 \mathrm{~ns}$ & $1.50 \mathrm{~ns}$ & $5.43 \mathrm{~ns}$ & 16.92 \\
\hline
\end{tabular}


TABLE 3.-Crop model predicted values for various parameters with the use of observed and randomly generated solar insolation data

\begin{tabular}{|c|c|c|c|c|c|c|c|c|}
\hline \multirow[b]{2}{*}{$\begin{array}{l}\text { Output } \\
\text { parameter }\end{array}$} & \multirow[b]{2}{*}{$\begin{array}{l}\text { Obs. solar } \\
\text { data }\end{array}$} & \multicolumn{6}{|c|}{$\begin{array}{l}\text { Parameter output with } \\
\text { randomly generated solar data }\end{array}$} & \multirow[b]{2}{*}{$\begin{array}{l}\text { Run mean } \\
\pm 95 \% \text { C.I. }\end{array}$} \\
\hline & & Runl & Run2 & Run3 & Run4 & Run5 & Run6 & \\
\hline Flowering date & 167 & 167 & 167 & 167 & 167 & 167 & 167 & 167 \\
\hline First pod & 171 & 171 & 171 & 171 & 171 & 171 & 171 & 171 \\
\hline Full pod & 173 & 173 & 173 & 173 & 173 & 173 & 173 & 173 \\
\hline Seeds/pod & 5.2 & 5.2 & 5.2 & 5.2 & 5.2 & 5.2 & 5.2 & 5.2 \\
\hline Physical maturity & 196 & 196 & 196 & 196 & 196 & 196 & 196 & 196 \\
\hline Pod yield (kg/ha) & 3055 & 3228 & 3230 & 3219 & 3273 & 3248 & 3068 & $3211 \pm 82.3$ \\
\hline Seed yield (kg/ha) & 2382 & 2516 & 2518 & 2439 & 2550 & 2531 & 2393 & $2491 \pm 69.4$ \\
\hline Shelling \% & 77.95 & 77.94 & 77.9 & 77.92 & 77.92 & 77.94 & 77.98 & $77.93 \pm .03$ \\
\hline Weight/seed $(g)$ & .172 & .174 & .175 & .168 & .177 & .175 & .166 & $0.173 \pm .005$ \\
\hline Seed \# (seeds $/ \mathrm{m}^{2}$ ) & 1386 & 1445 & 1441 & 1449 & 1438 & 1444 & 1442 & $1443 \pm 4.27$ \\
\hline Maximum LAI & 4.51 & 4.62 & 4.64 & 4.57 & 4.65 & 4.62 & 4.57 & $4.612 \pm .04$ \\
\hline Biomass (kg/ha) & 4490 & 4675 & 4755 & 4501 & 4772 & 4757 & 4568 & $4671 \pm 128.4$ \\
\hline Stalk (kg/ha) & 1293 & 1305 & 1372 & 1238 & 1353 & 1359 & 1352 & $1330 \pm 57.1$ \\
\hline Harvest Index & .530 & .538 & .530 & .542 & .534 & .532 & .524 & $0.533 \pm .007$ \\
\hline
\end{tabular}




\section{CONCLUSIONS}

A method for generating total solar radiation values for Isabela, Ponce and Mayaguez has been presented in this paper. In addition, it has been demonstrated that in locations where no solar radiation values are available, Choudhury's equations can be used to generate realistic daily total solar radiation values. It has also shown that these solar radiation values generated can be used effectively in crop simulation models. However, the "data crisis" issue remains unresolved. The availability of observed data for different sites around Puerto Rico was the main limitation in this research work.

The importance of having several years of measured data cannot be over-emphasized. This is to ensure proper validation of the weather generator models developed and generation of more reliable statistical parameters. The establishment of a network of stations at various

points on the island for the collection of total solar radiation is strongly recommended.

\section{LITERATURE CITED}

1. Beinroth, F. H., 1990. Agrotechnology transfer in the information age. Proc. 26th Carib. Food Crops Soc. Meeting, Mayaguez, Puerto Rico. pp. 378-88.

2. Choudhury, B., 1982. A parameterized model for global insolation under partially cloudy skies. Solar Energy 29: 479-86.

3. González, J., 1989. Modelaje de Procesos Térmicos de una Piscina Solar de Poca Profundidad para Puerto Rico y el Caribe. Tesis para el grado de maestro en ciencias, Universidad de Puerto Rico, Recinto de Mayagüez, Mayagüez, Puerto Rico.

4. Hoyt, D. V., 1978. A model for the calculation of solar global insolation. Solar Energy 21: $27-35$.

5. Hull, T. E. and D. D. F. Day, 1978. An Introduction to Programming and Applications with Fortran. Addison-Wesley Limited, Ontario, Canada. pp. 146-48.

6. IBSNAT Project, 1989. Soil and Weather Inputs for the IBSNAT Crop Models. IBSNAT 89 Symposium, Decision Support System for Agrotechnology Transfer; Part I. Proc. 81st, Annual Meeting of the American Society of Agronomy, Las Vegas, Nevada. pp. 31-45.

7. IBSNAT Project, 1990a. Documentation for IBSNAT Crop Model Input \& Output Files, Version 1.1: for the Decision Support system for Agrotechnology Transfer (DSSAT V2.1). Technical Report 5. Dept. of Agronomy and Soil Science, College of Tropical Agriculture and Human Resources, University of Hawaii, Honolulu, HI.

8. IBSNAT Project, 1990b. Report of the Midterm External Evaluation of the International Benchmark Sites Network for Agrotechnology Transfer (IBSNAT) Project. Dept. of Agronomy and Soil Science, College of Tropical Agriculture and Human Resources, University of Hawaii, Honolulu, HI.

9. Inglés, D. M., 1985. What Every Engineer Should Know About Computer Modelling: and Simulation. Marcel Dekker Inc., New York, N.Y.

10. Jones, J. W., 1989. Integrating models with expert systems and data bases for decision making. In: Proceedings of workshop on Climate and Agriculture: Systems Approach to Decision Making in Agriculture. A Weise (ed.). Univ. of South Carolina, Charleston, SC. pp. 194-21.3.

11. -- -, J. W. Mishoe and K. J. Boote, 1987. Introduction to Simulation and Modelling. Food and Fertilizer Technology Center. Technical Bulletin \$1.00. 
12. Little, T. M. and F. J. Hills, 1978. Agricultural Experimentation Design and Analysis. Joln Wiley and Sons Inc., Toronto, Canada.

13. Morgan, B. J. T., 1984. Elements of Simulation. Chapman and Hall Ltd., New York, N.Y.

14. Organick, E. I. and L. P. Meissner, 1974. FORTRAN IV Second Edition. AddisonWesley Publishing Company, Reading, MA.

15. Pérez, L. R., J. González and K. Soderstrom, 1992. A Model of Solar Insolation for Puerto Rico and the Caribbean. Solar Energy.

16. Shih, S. F. and K. S. Cheng, 1989. Generation of Synthetic and Missing Climatic Data for Puerto Rico. Water Resources Bulletin, American Water Resources Association, 25(4): 829-35.

17. Singh, U., G. Y. Tsuji and F. H. Beinxoth, 1990. Applications of Decision Support System for Agrotechnology Transfer in Present Day Agriculture. Proc. 26th Carib. Food Crops Soc. Meeting, Mayaguez, Puerto Rico. pp. 389-403.

18. Steel R. G. D. and J. H. Torrie, 1980. Principles and Procedures of Statistics. McGraw-Hill Inc., New York, N.Y.

19. Thornton, P. K. and J. B. Dent, 1990. Using Models to Explore Farming Alternatives. Agrotechnology Transfer, no. 11. IBSNAT Project, University of Hawaii, Hon., HI. pp. 1-9. 